\title{
The small open-economy New Keynesian Phillips Curve: empirical evidence and implied inflation dynamics
}

Article

Accepted Version

Mihailov, A., Rumler, F. and Scharler, J. (2011) The small open-economy New Keynesian Phillips Curve: empirical evidence and implied inflation dynamics. Open Economies Review, 22 (2). pp. 317-337. ISSN 0923-7992 doi: https://doi.org/10.1007/s11079-009-9125-9 Available at https://centaur.reading.ac.uk/17748/

It is advisable to refer to the publisher's version if you intend to cite from the work. See Guidance on citing.

To link to this article DOI: http://dx.doi.org/10.1007/s11079-009-9125-9

Publisher: Springer Verlag

All outputs in CentAUR are protected by Intellectual Property Rights law, including copyright law. Copyright and IPR is retained by the creators or other copyright holders. Terms and conditions for use of this material are defined in the End User Agreement.

www.reading.ac.uk/centaur 
Central Archive at the University of Reading

Reading's research outputs online 


\title{
The Small Open-Economy New Keynesian Phillips Curve: Empirical Evidence and Implied Inflation Dynamics*
}

\author{
Alexander Mihailov ${ }^{\dagger} \quad$ Fabio Rumler Johann Scharler $^{\ddagger}$
}

May 25, 2009

\begin{abstract}
In this paper we apply GMM estimation to assess the relevance of domestic versus external determinants of CPI inflation dynamics in a sample of OECD countries typically classified as open economies. The analysis is based on a variant of the small open-economy New Keynesian Phillips Curve derived in Galí and Monacelli (2005), where the novel feature is that expectations about fluctuations in the terms of trade enter explicitly. For most countries in our sample the expected relative change in the terms of trade emerges as the more relevant inflation driver than the contemporaneous domestic output gap.
\end{abstract}

Key words: New Keynesian Phillips Curve, small open economies, expected terms of trade fluctuations, inflation dynamics, GMM estimation.

JEL classification codes: C32, C52, E31, F41.

\footnotetext{
${ }^{*}$ We would like to thank an anonymous referee, the Managing Editor George Tavlas, Kerry Patterson and the audience at the 2nd International Conference on Small Open Economies in a Globalized World, Wilfrid Laurier University, Waterloo, Ontario, Canada (June 2008) for helpful comments. The usual disclaimer applies.

${ }^{\dagger}$ University of Reading, School of Economics, Whiteknights, Reading RG6 6AA, United Kingdom; a.mihailov@reading.ac.uk.

${ }^{\ddagger}$ Oesterreichische Nationalbank, Economic Analysis Division, Otto Wagner Platz 3, A-1090 Vienna, Austria; Fabio.Rumler@oenb.at.

${ }^{\S}$ University of Linz, Department of Economics, Altenbergerstrasse 69, A-4040 Linz, Austria; Johann. Scharler@jku.at.
} 


\section{Introduction}

The New Keynesian Phillips Curve (NKPC) is a key ingredient in what currently appears to be the workhorse model for business cycle analysis and evaluation of monetary policy. In fact, the NKPC is one of the structural-form equations in the so-called New Keynesian (NK) model. Starting with Galí and Gertler (1999), many authors have estimated various specifications of the NKPC - see, e.g., Galí, Gertler and López-Salido (2001, 2003, 2005), Rudd and Whelan (2005, 2006) and Sbordone $(2002,2005,2007) .{ }^{1}$ However, most available estimates are inferred from a closed-economy context, usually employing the generalized method of moments (GMM) to handle expectational terms. The purpose of this paper is to evaluate the role of expected fluctuations in the terms of trade for inflation dynamics in small open economies, based on the small open-economy (SOE) version of the NKPC derived in Galí and Monacelli (2005), henceforth the SOE NKPC. Notably, the SOE NKPC links inflation dynamics to externalsector macro-variables, such as the terms of trade (ToT), in addition to domestic ones.

Our analysis is partly related to Leith and Malley (2007) and Rumler (2007), who also estimate open-economy versions of the NKPC although in a less explicit way. In contrast to our paper, these authors focus on parameters such as the degree of backward- and forwardlookingness, the Calvo probability of a price change, and the degree of imperfect substitutability between domestic and foreign intermediate inputs, without examining in more detail the role of external-sector inflation drivers. ${ }^{2}$ The novel aspect in this paper is that we apply the openeconomy NKPC of Galí and Monacelli (2005) which allows us to analyze domestic and external factors in determining CPI inflation dynamics.

We estimate several empirical specifications of the the open-economy NKPC derived in Galí and Monacelli (2005) by GMM. We use data from a sample of ten OECD countries typically classified as SOEs and covering the period since the early 1970s. We find that for most countries in our sample, the expected relative change in the terms of trade emerges as a more relevant factor driving CPI inflation than the contemporaneous domestic output gap. Therefore, we conclude that the inflation rate in small open economies is indeed driven by expectations about external factors to a substantial degree.

The paper is structured as follows. The next section outlines our empirical strategy and derives the estimating equation. Section 3 describes our data set while 4 presents our estimation

\footnotetext{
${ }^{1}$ Rudd and Whelan (2007) present a critical review of this literature.

${ }^{2}$ Razin and Yuen (2002) highlight the theoretical similarities and differences of closed- versus open-economy NKPC formulations. Razin and Binyamini (2007) investigate empirical issues related to the flattening of the inflation-output tradeoff and whether this could be assigned to monetary policy or globalization.
} 
results. The last section concludes the paper.

\section{Theoretical Motivation and Empirical Strategy}

Our analysis is based on the model described in Galí and Monacelli (2005). They show that in a small open economy consumer-price inflation, $\pi_{t}$ is determined by domestic-price inflation, $\pi_{H, t} \equiv p_{H, t}-p_{H, t-1}$, and the change in the terms of trade, $\Delta s_{t} \equiv s_{t}-s_{t-1}$, with $s_{t} \approx p_{F, t}-p_{H, t}$, where $s_{t}$ is the (natural) log of the effective ToT of the SOE vis-à-vis the rest of the world and $p_{H, t}$ and $p_{F, t}$ are the (natural) logs of its domestic price index and import price index, respectively.

In particular, the following equation holds as a log-linear approximation around the steady state: ${ }^{3}$

$$
\pi_{t}=\pi_{H, t}+\alpha \Delta s_{t}
$$

where $\alpha \in[0,1]$ is inversely related to the degree of home bias in consumption preferences. The equation states that the gap between consumer- and domestic-price inflation is proportional to the per cent change of the terms of trade, with the coefficient of proportionality given by the index of openness. In other words, CPI inflation is determined by domestic-price inflation, a domestic factor, and changes in the terms of trade, an external factor, which matter more the more open the economy is.

A further implication of the Galí-Monacelli (2005) model is the following variant of the NKPC: ${ }^{4}$

$$
\pi_{t}=\beta E_{t} \pi_{H, t+1}+\lambda \widehat{m c}_{t}+\alpha \Delta s_{t}
$$

Equation (2) is analogous to the NKPC typically derived and estimated for a closed economy, where $\widehat{m c}_{t}$ is real marginal cost in per cent deviation from its steady state value. Furthermore, since (1) implies that $E_{t} \pi_{H, t+1}=E_{t} \pi_{t+1}-\alpha E_{t} \Delta s_{t+1}$ we can rewrite (2) as:

$$
\pi_{t}=\beta\left(E_{t} \pi_{t+1}-\alpha E_{t} \Delta s_{t+1}\right)+\lambda \widehat{m c}_{t}+\alpha \Delta s_{t} .
$$

After rearranging terms, we arrive at

$$
\pi_{t}=\beta E_{t} \pi_{t+1}+\lambda \widehat{m c}_{t}+\alpha\left(\Delta s_{t}-\beta E_{t} \Delta s_{t+1}\right) .
$$

Since $\widehat{m c}_{t}$ can be shown to be proportional to the SOE's output gap, $x_{t}$, the NKPC for the

\footnotetext{
${ }^{3}$ For details, see Appendix A and Galí and Monacelli (2005).

${ }^{4}$ This equation follows directly from equations (14) and (32) in Galí and Monacelli (2005).
} 
SOE can alternatively also be expressed as, ${ }^{5}$

$$
\pi_{t}=\beta E_{t} \pi_{t+1}+\kappa_{\alpha} x_{t}+\alpha\left(\Delta s_{t}-\beta E_{t} \Delta s_{t+1}\right)
$$

where $\kappa_{\alpha} \equiv \lambda\left(\sigma_{\alpha}+\varphi\right), \lambda \equiv \frac{(1-\beta \theta)(1-\theta)}{\theta}, \sigma_{\alpha} \equiv \frac{\sigma}{(1-\alpha)+\alpha \omega}$, and $\omega \equiv \sigma \gamma+(1-\alpha)(\sigma \eta-1)$; furthermore, $\sigma$ is the inverse of the intertemporal elasticity of substitution in consumption and $\varphi$ is an analogous parameter characterizing the intertemporal labor/leisure choice, $\theta$ is related to the degree of price stickiness (as $1-\theta$ is the probability of adjusting prices in a Calvo (1983) setting, $0<\beta \equiv \frac{1}{1+\rho}<1$ is the standard time discount factor, with $\rho$ being the time discount rate, and $\eta>0$ is the intratemporal substitutability in consumption between the SOE's domestically-produced and imported goods.

According to (5), CPI inflation is driven by the domestic output gap, expected next-period CPI inflation and the expected, discounted change in the terms of trade relative to the observed past-to-current period ToT change. Intuitively, an expected improvement in the ToT in the next relative to the current period $\left(\Delta s_{t}>\beta E_{t} \Delta s_{t+1}\right)$ would increase current demand for domestic goods because their price is relatively lower than what is expected in the future and this increased demand exerts upward pressure on current inflation. This pressure is stronger the higher is the degree of openness to trade, $\alpha$. Inversely, an expected deterioration of the ToT in the next relative to the current period $\left(\Delta s_{t}<\beta E_{t} \Delta s_{t+1}\right)$ would lower current-period demand for domestic goods as agents expect their relative price to decline in the future and thus exerts downward pressure on current inflation. This pressure is stronger the higher the degree of openness to trade. Evaluating empirically the role of this forward-looking relative ToT change channel in inflation dynamics as reflected in the SOE NKPC constitutes the novelty of our approach relative to the existing literature.

Our empirical analysis is based on equations (4) and (5). Since the ToT enter explicitly along with domestic drivers of CPI inflation, these two equations are a natural starting point for a comparison of domestic and external factors relevant for inflation dynamics. More specifically, we apply GMM estimation since, under rational expectations, (4) and (5) imply sets of orthogonality conditions.

Although our analysis bears some resemblance to the studies by Leith and Malley (2007) and Rumler (2007), in our model the open-economy elements enter as a separate expression in

\footnotetext{
${ }^{5}$ Theoretically defined as the deviation of the sticky-price output level from the output level when all prices are perfectly flexible; empirically measured most frequently as the deviation of actual output from 'potential' output proxied by trend output, as we do and explain further down.
} 
the NKPC while in their model they are included in the marginal cost measure. Thus, while we use the output gap and real unit labor cost as proxies for marginal cost, depending on the specification, they use a marginal cost measure that accounts for open-economy factors, i.e. real unit labor cost adjusted for imported intermediate inputs prices. Hence, external factors figure more prominently in our analysis.

\section{Data Description}

We estimate equations (4) and (5) for ten advanced OECD countries which are typically classified as small open economies (and also selected according to data availability and to maximize comparability): Austria, Canada, France, Germany, Italy, the Netherlands, Spain, Sweden, Switzerland and the United Kingdom. We include France, Germany and the UK even if they are not small countries since they are fairly open and interdependent in terms of consumption structure, whereas we do not consider the US and Japan which have a much lower import share in consumption.

All data (for the CPI, GDP and the import and export prices for the construction of the terms of trade as well as compensation to employees) stem from the Economic Outlook (ECO) database of the OECD. In each specification, the dependent variable is quarter-on-quarter CPI inflation. In estimating specification (5), we employ two different proxies for the output gap, namely the deviation of real GDP from a Hodrick-Prescott (H-P) trend, and its deviation from a quadratic-polynomial (Q-P) trend. ${ }^{6}$ To solve the well-known endpoint problem of any one-sided filtering method, the H-P and Q-P trend have been calculated including forecast values up to 2009:4 available at the ECO database. The H-P output gap has additionally been normalized by its standard deviation to ensure comparable magnitudes across countries.

In line with the approaches implemented with respect to the closed-economy NKPC, notably following Galí and Gertler (1999) and Sbordone (2002), we also estimate specification (4) using average real unit labor costs as a proxy for real marginal costs instead of the output gap. Empirically, average real unit labor cost is proxied by the labor share in income, $\frac{W l}{P y}$, where $W$ is hourly compensation, $l$ total hours worked, $y$ real output and $P$ a measure of the (relevant) price level. ${ }^{7}$ We construct this variable by dividing total nominal compensation to employees

\footnotetext{
${ }^{6}$ These commonly applied empirical measures of the output gap are, certainly, only imperfect proxies to the theoretically relevant output gap. The underlying detrending procedures, which postulate a specific functional form to separate the trend (or potential) real GDP from the cyclical component, are sometimes referred to as 'naive' in the literature. The alternatives in applied work, though, are not obvious.

${ }^{7}$ Most empirical studies have found a negative correlation between the labor share in income and the traditional, 'naive' measures of the output gap. For that reason, the notorious problem of wrongly signed (i.e.,
} 
by nominal GDP. As detrending method we use the Q-P trend in this case.

To construct the effective ToT, $s_{t}$, which in our model corresponds to $p_{F, t}-p_{H, t}$, we calculate - assuming producer's currency pricing - the log difference of the import prices (given by the import deflator) and the export prices (given by the export deflator) for each country. Implicitly, this ratio gives the effective ToT because the importance of the trading partners is automatically reflected in the deflators.

Our data covers the period from the first quarter of 1970 to the last quarter of 2007, where the samples vary somewhat due to limited data availability for some countries. All estimations are from 1970:1 to 2007:4, with the following exceptions. For Austria, all data are available only from 1980 on. Specification (4) is estimated from 1975 for Italy and from 1980 for Spain because compensation of employees is available only from these respective years on. For Switzerland, specification (4) could not be estimated due to the lack of quarterly data on compensation.

The instruments used in the GMM estimation have been chosen for each country individually. We do not restrict instrument sets to be identical across countries since inflation dynamics may - to some extent - be country-specific. As it is standard in the literature, the instrument sets mainly consist of lags of the right-hand-side variables in equations (4) and (5). In addition to lagged regressors, we use commodity prices and the bilateral USD/EUR exchange rate as instruments for some countries which also proved informative for future inflation. The instruments should be correlated with the right-hand-side variables but uncorrelated with the residuals of the equation implying a set of orthogonality conditions. We choose the specific lag structure of the instruments according to these two criteria, where we use the $J$-test to test the validity of the overidentifying restrictions. The complete set of instrumental variables by country and econometric specification is provided in Appendix C.

\section{Estimation Results}

In this section we present our estimation results for equations (4) and (5). We start with (5) as our main specification as it is the most intuitive and straightforward to estimate. We proxy the output gap, $x_{t}$, by the deviation of real GDP from its H-P trend.

Table 1 shows the results. The $p$-values associated with the $J$-test statistics are reported in the last column. The null of the validity of the overidentifying restrictions cannot be rejected at standard levels of significance.

statistically significant and negative) output gaps found in the data has been often avoided by employing the labor share as a proxy for real marginal costs; see Galí and Gertler (1999) and Galí, Gertler and López-Salido (2001). 
[Table 1 about here]

We see that the time discount factor $\beta$ is statistically significant in all countries and the point estimate is slightly below unity, except for Italy and France. For these two countries we estimate $\beta$ to be only marginally above unity. ${ }^{8}$

Turning to $\kappa_{\alpha}$, the parameter that measures the impact of the output gap on inflation, we see that this parameter is significantly greater than zero only in France and the UK. For Sweden, the point estimate for $\kappa_{\alpha}$ is significantly negative. Intuitively, higher output gaps are associated with an increase in marginal costs, which translate into price pressure. Therefore, one would expect $\kappa_{\alpha}$ to be generally positive. However, as we demonstrate in Appendix B, this need not be the case in the model in Galí and Monacelli (2005). Moreover, several authors argue that a shortcoming of the standard New Keynesian framework is that it does not allow for a trade-off between inflation and output stabilization. ${ }^{9}$ Thus, it might be the case that despite the fact that our estimated equation is based on a model which does not generally allow for this type of trade-off, our estimate for $\kappa_{\alpha}$ actually picks up the effect of real rigidities insofar these are present in the data. In any case, in the majority of the countries in our sample the output gap turns out to be insignificant, which casts some doubt on the importance of domestic factors for inflation dynamics in small open economies relative to external factors, as we claim below. Yet, 'wrongly' (i.e., negatively) signed or insignificant output gaps are known to have plagued the closed-economy empirical NKPC literature too (see Rudd and Whelan, 2007).

Our estimates for $\alpha$, the parameter we are mostly interested in, are positive and significant at standard levels for half of the countries in our sample: namely, at the $1 \%$ level for Germany, the Netherlands, the UK and Switzerland, and at the $10 \%$ level for Canada. Thus, external factors appear to be more relevant than the domestic output gap as inflation divers in the small open economies in our sample. Recall that in Galí and Monacelli (2005) $\alpha$ corresponds to the share of domestic consumption allocated to imported goods in the steady state. Clearly, a negative estimate for $\alpha$ is inconsistent with this interpretation. Thus, it appears that the model in Galí and Monacelli (2005) does not fully capture all factors influencing the impact of terms of trade fluctuations on inflation dynamics. A particularly relevant such factor seems the pricing behavior of exporting firms. As mentioned, the Galí-Monacelli (2005) model is based on

\footnotetext{
${ }^{8}$ This is not uncommon in the empirical NKPC literature employing GMM: e.g., Rudd and Whelan (2007), Table 1, p. 159, similarly report discount factors slightly higher than unity for quarterly US estimates over 1960:1-2004:3.

${ }^{9}$ Blanchard and Galí (2007) dub this property the 'divine coincidence': stabilizing the welfare-relevant output gap at the same time stabilizes inflation. They explain it with the absence of real imperfections in the NK framework and show that once real wage rigidity is introduced the property holds no longer.
} 
full producer currency pricing. However, if prices are actually set according to local currency pricing in some proportion, then our estimates of $\alpha$ may be affected by this feature, itself likely to be highly country-specific. Note also that the degree of trade openness we estimate ranges from $14 \%$ (Canada, which is, inversely, a home bias of $86 \%$ ) to $48 \%$ (UK, i.e., a home bias of $52 \%)$.

In short, we conclude that expected relative variations in the terms of trade appear to be an important driver of CPI inflation in the majority of countries under consideration. Moreover, the impact of domestic factors on inflation dynamics, summarized by the output gap, come out to be of less importance. To be more precise, the output gap is statistically significant at the $5 \%$ level for three out of ten countries, namely, France, the UK and Sweden. Only in the UK both the expected relative ToT change and the current output gap are simultaneously significant, together with expected next-period CPI inflation as the third factor in our main estimating equation (5). Nevertheless, for three countries, Austria, Italy and Spain, we find that neither the output gap, nor the terms of trade change turn out to be significant.

[Table 2 about here]

As a next step in our analysis, we re-estimate (5) but this time with the output gap calculated as deviation of real GDP from a quadratic-polynomial (Q-P) trend. Table 2 demonstrates a slight improvement of our results in terms of our estimates for $\alpha$. In addition to being rather robust to this modification, the outcome from this latter estimation also yields a sixth country, Italy, where the expected relative ToT change now becomes statistically significant at the $10 \%$ level and acquires a plausible positive magnitude of 0.31 . However, the above improvement comes at some cost: when estimating (5) with Q-P instead of H-P filtering, the output gap coefficient, $\kappa_{\alpha}$, turns out to be insignificant in all countries in the sample except France. As before, the estimated $\beta$ 's are all significant at the $1 \%$ level and show plausible values.

Recall from Section 2 that $\kappa_{\alpha}$ in (5) is a convolution of the primitive parameters of the model. In this sense, $\kappa_{\alpha}$ can be interpreted as a 'reduced-form' parameter. Thus, our estimations so far were essentially 'semi-structural' in the sense that although our estimating equation is motivated by the theory, we do not identify all primitive parameters of the model. In particular, $\alpha$ enters the construction of $\kappa_{\alpha}$. Thus, by treating $\kappa_{\alpha}$ and $\alpha$ as independent coefficients in our estimations, we do not take into account that the theory puts a restriction on these parameters. Note, however, that the parameter we are most interested in, $\alpha$, is a primitive parameter. Nevertheless, to properly account for this restriction imposed by the theory, we now estimate 
the structural parameters of the model.

In order to be able to identify all the structural parameters we are interested in, we need to calibrate the remaining parameters. In particular, we set $\sigma=1, \gamma=1, \varphi=3$ and $\eta=4$, which appear to be widely accepted in the literature (see Obstfeld and Rogoff, 2001) and are largely chosen in accordance with the calibration in Galí and Monacelli (2005)..$^{10}$

Table 3 shows the estimates for the structural parameters. In addition to $\beta$ and $\alpha$ we now also obtain estimates for the Calvo parameter $\theta$. Although our estimates for $\theta$ imply a higher degree of price rigidity than commonly found in micro studies on price setting, our results are quite in line with the literature on the standard NKPC (see e.g. Galí and Gertler, 1999), but our estimates are somewhat higher than in papers where the standard model has been refined by introducing real frictions. ${ }^{11}$

When we compare our results to those in the related papers of Leith and Malley (2007) and Rumler (2007) for their specifications of the NKPC, we see that our estimates for $\theta$ are only in a comparable range for Germany and France. ${ }^{12}$ For the remaining countries they are consistently lower in those papers.

[Table 3 about here]

We also see from the table that the coefficient estimates for $\alpha$ closely match those presented in Table 2. Overall, the results in Table 3 support our previous conclusion that terms of trade dynamics are an important source of variation in CPI inflation in small open economies.

It is well known that the output gap and marginal costs do not need to be proportional, whereas our estimated equation (5) relies on the assumption that they are indeed. Galí and Gertler (1999) and Sbordone (2002) were among the first to argue that a more general approach would be to use average real unit labor costs to proxy marginal costs.

[Table 4 about here]

\footnotetext{
${ }^{10}$ Note that our calibration of $\eta$ differs from Galí and Monacelli (2005) who use $\eta=1$. Their calibration, however, creates a special case where the restriction of $\alpha$ appearing in the reduced-form coefficient is eliminated. Because we want to estimate this additional restriction, we have to adopt a value for $\eta$ different from 1 . Furthermore, it is more plausible that $\eta$ is greater rather than smaller than 1 (see Obstfeld and Rogoff, 2001). As a robustness check, we used alternative plausible values for all calibrated parameters. Our results proved to be quite robust to changes in the calibrated values.

${ }^{11}$ It has been shown that introducing real frictions into the model such as firm-specific capital (as in Woodford, 2005) or decreasing returns to scale in the production function (as in Galí et al., 2001) leads to lower estimates of $\theta$ for a given reduced-form coefficient.

${ }^{12}$ See tables 1 in Leith and Malley (2007) and in Rumler (2007).
} 
Thus, we proceed by estimating equation (4) directly, where we proxy $\widehat{m c}_{t}$ by the average real unit labor costs. We see from Table 4 that this modification leads to rather similar outcomes. Now $\lambda$ is still insignificant (in nine out of the ten economies in our sample) or wrongly signed (for the UK, the only country where it comes out significant, at the $1 \%$ level). On the other hand, we get estimates for $\alpha$ that are statistically significant at the $1 \%$ level and plausible in four cases (Germany, Italy, the Netherlands and the UK). Overall, for the remaining six countries in the sample we find that neither the current-period labor share in income, nor the expected next-period change in the terms of trade relative to that observed since the past period matter for the dynamics of the CPI inflation rate. Thus, this specification performs relatively worse, which is in line with the criticism in Rudd and Whelan (2007).

As an additional robustness check, we present the estimated primitive parameters of equation (4) in Table 5. Again, as for equation (5) we find that the results of the structural estimation of equation (4) broadly match those obtained for the semi-structural estimation.

[Table 5 about here]

Note that the specifications estimated so far impose rather strong theoretical restrictions on how the terms of trade enter and influence inflation dynamics. In particular, the parameter $\beta$ determines how expected inflation, and the expected ToT enter into (4) and (5). Moreover, since $\beta$ is close to unity in most cases, the last term in (5) resembles the second difference of the terms of trade. Empirically, the second difference of the ToT behaves very much like white noise in most countries. This could be one reason why the estimates of $\alpha$ turn out to be insignificant or negatively signed in some of the countries. Thus, regardless of the theoretical justification in Galí and Monacelli (2005), as an additional robustness analysis we estimate an alternative specification motivated on empirical grounds (only) which replaces $\left(\Delta s_{t}-\beta E_{t} \Delta s_{t+1}\right)$ simply by $\Delta s_{t}$. Of course, this additional specification does not allow to interpret the coefficients on the output gap and on the terms of trade in a structural way.

[Table 6 about here]

Table 6 shows the results. We see that this less restrictive specification delivers broadly similar results. In particular, now the first difference of the terms of trade comes out significant in six countries, whereas the output gap is significantly different from zero in three countries.

[Tables 7 and 8 about here] 
To further cross-check our findings, we compare our open-economy results to what we obtain based on closed-economy specifications. More specifically, we estimate a purely forward-looking and a hybrid version of the closed-economy NKPC. For the hybrid specification we add the lagged inflation rate as an additional explanatory variable.

The results based on the purely forward-looking closed-economy NKPC in Table 7 show a positive and significant coefficient on the output gap for four out of ten countries, which is a marginally better performance than in our baseline specification in Table 1. From this finding we may conclude that the inclusion of expected relative ToT fluctuations in the SOE specification of the NKPC may slightly contribute to the loss of significance of the output gap. For the hybrid model, in contrast, the results for the output gap - shown in Table 8 - do not improve compared to the SOE NKPC estimation in Table 1. Thus, in our sample, including lagged inflation in the NKPC does not solve the problem of insignificant or wrongly signed output gap coefficients often found in the literature. ${ }^{13}$

In short, these cross-checks reassure us that terms of trade fluctuations are a non-negligible source of inflation dynamics in small open economies. As an additional dimension of our analysis, we estimate (5) over subsamples. This dimension is motivated by a number of recent studies which discuss the potential implications of the ongoing process of globalization for inflation dynamics (see, e.g., Rogoff, 2003 and 2006, among others). Borio and Filardo (2007) and White (2008) argue that due to increased openness and the resulting increase in trade and financial flows, traditional domestic factors have become less important in determining inflation. The opposite strand of the literature - e.g., Ball (2006), Woodford (2007), Mishkin (2007, 2009) concludes that there is no evidence for a strong effect of globalization in determining domestic inflation.

We perform the estimations for the two subsamples 1970:1-1986:4 and 1987:1-2007:4. ${ }^{14}$ We choose this particular approach since it splits our sample in equal halves and also because the late 1980s saw substantial financial liberalizations and increases in international trade. For Germany we choose the sample split date to be 1991, i.e., the two subsamples are 1970:1-1990:4 and 1991:1-2007:4, because of the break induced by the German re-unification. Since data for Austria start in 1980 and due to its close economic links with Germany, we choose the break date for Austria to be 1991 as well.

\footnotetext{
${ }^{13}$ Additionally estimating the SOE NKPC in an empirically motivated hybrid form, i.e. adding a lagged inflation term in equation (5), does not deliver a better fit than the original SOE NKPC. In particular, our main conclusion that the external inflation driver is more relevant for explaining inflation than the domestic output gap survives also in this estimation. The results are available upon request.

${ }^{14}$ The instruments are the same in the estimations of the two subsamples.
} 
Tables 9 and 10 show the results for the subperiods. We report only the estimates for the specification with H-P detrended real GDP as a proxy for the output gap. Results obtained for the other specifications are qualitatively similar. ${ }^{15}$ Comparing the estimates for $\kappa_{\alpha}$ across subsamples shows that the output gap becomes somewhat less important as a driving force of inflation over time. In the first subsample $\kappa_{\alpha}$ is significantly different from zero at the $5 \%$ level in five countries. In the second subsample, we find only three countries where the output gap enters significantly at the $5 \%$ level, while the latter has lost significance in all five countries of the first subsample. In Switzerland the output gap is only significant at the $10 \%$ level, coming out as positive at 0.10 , whereas being negative at -0.14 in the earlier subperiod. Thus, if at all there is a pattern in our results, we find some indications for a slightly reduced sensitivity of CPI inflation dynamics to domestic output gaps overall in our sample, which is roughly in line with Borio and Filardo (2007) and White (2008).

[Tables 9 and 10 about here]

For $\alpha$, however, we find a similarly inconclusive pattern. In the later subsample $\alpha$ is significantly different form zero in three countries, compared to five countries in the earlier sample. Note as well that, numerically, we obtain larger point estimates in the second subsample for all three economies where $\alpha$ is significantly greater than zero. More precisely, $\alpha$ has risen across the subperiods studied from 0.07 in the 1970 s and the 1980 s to 0.14 in the 1990 s and the $2000 \mathrm{~s}$ in Italy, from 0.47 to 0.84 in the UK and from 0.21 to 0.27 in the Netherlands. With no overwhelming evidence of globalization effects along these estimates in our sample, the latter trends are perhaps indicative for a potential role of country-specific features at the level of production and trade structures as well as of policy and institutional mechanisms in explaining the divergence of the mentioned three countries from the other countries in our sample. In two countries, Austria and Germany, $\alpha$ actually decreased in the later subperiod relative to the earlier one, in Sweden it increased but lost its significance, and in the other four countries it remained insignificant.

Thus, although the economies in our sample may have become more open over time, we do not find that changes in the expected relative ToT have become a more important determinant of inflation dynamics in the majority of countries. Yet, whereas the number of countries for which the terms of trade are a key determinant of inflation dynamics has decreased, its relative importance in the economies of our sample where it remains relevant (three cases) has considerably increased.

\footnotetext{
${ }^{15}$ We also estimated specifications where GDP is detrended using a Q-P trend and where unit labor costs replace the output gap. These results are available upon request.
} 


\section{Concluding Remarks}

In this paper we explore the role of terms of trade fluctuations for inflation dynamics. Our analysis is based on the small open-economy version of the New Keynesian Phillips Curve derived in Galí and Monacelli (2005). The SOE NKPC contains an additional explicit term capturing ToT fluctuations, and hence allows a comparison of the relevance of domestic versus external factors as driving forces of CPI inflation dynamics. For most economies in the sample we considered, expected relative changes in the ToT turned out to be a more important CPI inflation driver than the contemporaneous domestic output gap. Evaluating empirically the role of this forward-looking relative ToT change channel for inflation dynamics is the main contribution of our paper.

Note that although our emphasis is on the quantification of domestic versus external factors driving dynamics, our analysis can also be viewed as a test of the underlying theory to a certain extent. For most countries and in most specifications parameter estimates fall within ranges that are admissible from the point of view of the theory, which provides some support in favor of the model. However, although our results suggest that terms of trade fluctuations drive inflation dynamics, we also find that the terms of trade and the domestic output gap are simultaneously significant only in a few cases. Put differently, the idea that inflation dynamics are jointly determined by domestic and external factors receives only limited support in our analysis.

Our estimates are not conclusive either concerning the potential effects of globalization on inflation dynamics, although we find that for about one-third of the countries in our sample the role of external factors does seem to have increased in quantitative terms over time. Needless to say, globalization may not be the only factor contributing to this outcome. Factors such as the specific size, production structure and/or trade patterns of a particular country may have contributed, in addition to global trends, to a stronger or weaker influence of external versus domestic factors. Separating out and quantifying the effects along these dimensions, as well as other refinements of our initial broad estimates reported here, constitute interesting avenues for further theoretical and empirical research. More disaggregated data and alternative modeling of the pricing behavior of firms or of real rigidities in an international model environment are also among the areas for future exploration. 


\section{References}

[1] Ball, Lawrence (2006), "Has Globalization Changed Inflation?", NBER Working Paper No. 12687 (October).

[2] Blanchard, Olivier and Jordi Galí (2007), "Real Wage Rigidities and the New Keynesian Model", Journal of Money, Credit and Banking 39 (s1, February), 35-65.

[3] Borio, Claudio and Andrew Filardo (2007), "Globalisation and Inflation: New CrossCountry Evidence on the Global Determinants of Domestic Inflation," Bank for International Settlements Working Paper 227 (May), Basle.

[4] Calvo, Guillermo (1983), "Staggered Prices in a Utility-Maximizing Framework", Journal of Monetary Economics 12, 383-398.

[5] Dixit, Avinash and Joseph Stiglitz (1977), "Monopolistic Competition and Optimum Product Diversity," American Economic Review 67 (3, June), 297-308.

[6] Galí, Jordi and Mark Gertler (1999), "Inflation Dynamics: A Structural Econometric Approach," Journal of Monetary Economics 44 (2), 195-222.

[7] Galí, Jordi and Mark Gertler and David López-Salido (2001), "European Inflation Dynamics," European Economic Review 45 (7), 1237-1270.

[8] Galí, Jordi and Mark Gertler and David López-Salido (2003), "Erratum to European Inflation Dynamics," European Economic Review 47 (4), 759-760.

[9] Galí, Jordi and Mark Gertler and David López-Salido (2005), "Robustness of Estimates of the Hybrid New Keynesian Phillips Curve," Journal of Monetary Economics 52, 11071118.

[10] Galí, Jordi and Tommaso Monacelli (2005), "Monetary Policy and Exchange Rate Volatility in a Small Open Economy," Review of Economic Studies 72, 707-734.

[11] Leith, Campbell and Jim Malley (2007), "Estimated Open Economy New Keynesian Phillips Curves for the G7," Open Economies Review 18, 405-426.

[12] Mishkin, Frederic (2007), "Inflation Dynamics," International Finance 10 (3), 317-334.

[13] Mishkin, Frederic (2009), "Globalization, Macroeconomic Performance, and Monetary Policy", Journal of Money, Credit and Banking 41 (s1, February), 187-196. 
[14] Obstfeld, Maurice and Kenneth Rogoff (2001), "The Six Major Puzzles in International Macroeconomics: Is There a Common Cause?", in NBER Macroeconomics Annual 2000, Volume 15, 339-412, National Bureau of Economic Research, Inc.

[15] Razin, Assaf and Chi-Wa Yuen (2002), "The 'New Keynesian' Phillips Curve: Closed Economy versus Open Economy," Economics Letters 75, 1-9.

[16] Razin, Assaf and Alon Binyamini (2007), "Flattened Inflation-Output Trade-off and Enhanced Anti-Inflation Policy: Outcome of Globalization?", NBER Working Paper No. 13280 (July).

[17] Rogoff, Kenneth (2003), "Globalization and Global Disinflation," in Monetary Policy and Uncertainty: Adapting to a Changing Economy, a symposium sponsored by the Federal Reserve Bank of Kansas City, Jackson Hole, Wyoming (August).

[18] Rogoff, Kenneth (2006), "Impact of Globalization on Monetary Policy," in The New Economic Geography: Effects and Policy Implications, a symposium sponsored by the Federal Reserve Bank of Kansas City, Jackson Hole, Wyoming (August).

[19] Rudd, Jeremy and Karl Whelan (2005), "New Tests of the New-Keynesian Phillips Curve", Journal of Monetary Economics, 52 (6, September), 1167-1181.

[20] Rudd, Jeremy and Karl Whelan (2006), "Can Rational Expectations Sticky-Price Models Explain Inflation Dynamics?", American Economic Review 96, 303-320.

[21] Rudd, Jeremy and Karl Whelan (2007), "Modeling Inflation Dynamics: A Critical Review of Recent Research", Journal of Money Credit and Banking 39 (1, February), 155-170.

[22] Rumler, Fabio (2007), "Estimates of the Open Economy New Keynesian Phillips Curve for Euro Area Countries", Open Economies Review 18, 427-451.

[23] Sbordone, Argia (2002), "Prices and Unit Labor Costs: A New Test of Price Stickiness," Journal of Monetary Economics 49 (2), 235-456.

[24] Sbordone, Argia (2005), "Do Expected Future Marginal Costs Drive Inflation Dynamics?", Journal of Monetary Economics 52, 1183-1197.

[25] Sbordone, Argia (2007), "Globalization and Inflation Dynamics: The Impact of Increased Competition," NBER Working Paper No. 13556 (October). 
[26] White, William (2008), "Globalisation and the Determinants of Domestic Inflation," Bank for International Settlements Working Paper 250 (March), Basle.

[27] Woodford, Michael (2005), "Firm-Specific Capital and the New-Keynesian Phillips Curve", International Journal of Central Banking 1(2), 1-46.

[28] Woodford, Michael (2007), "Globalization and Monetary Control", NBER Working Paper No. 13329 (August). 


\section{A CPI Inflation and the Terms of Trade}

As Galí and Monacelli (2005) point out, equation (1) holds in approximation since the effective (i.e., multilateral) terms of trade of the SOE are, more precisely, defined by

$$
S_{t} \equiv \frac{P_{F, t}}{P_{H, t}}=\left(\int_{0}^{1} S_{i, t}^{1-\gamma} d i\right)^{\frac{1}{1-\gamma}}
$$

where $\gamma>0$ measures the substitutability between goods produced in different countries other than the SOE indexed by $i$ (and, thus, entering its import-price index), which can be approximated (up to first order) by the log-linear expression

$$
s_{t}=\int_{0}^{1} s_{i, t} d i .
$$

Moreover, log-linearization of the CPI Dixit-Stiglitz (1977) constant elasticity of substitution aggregator common to such frameworks,

$$
P_{t} \equiv\left[(1-\alpha) P_{H, t}^{1-\eta}+\alpha P_{F, t}^{1-\eta}\right]^{\frac{1}{1-\eta}}
$$

where $\eta>0$ is the substitutability between the SOE's domestically-produced and imported goods (i.e., those produced in the rest of the world), around a symmetric steady state satisfying the purchasing power parity condition, $P_{H, t}=P_{F, t}$ under assumed full producer currency pricing and $\bar{S}=1$, implies

$$
p_{t} \equiv p_{H, t}+\alpha s_{t}
$$

The last expression above, taken in differences, in fact leads to (1).

\section{B Theoretically Expected Sign of $\kappa_{\alpha}$}

From the signs of the enumerated components in the definition of $\kappa_{\alpha}$ in the SOE NK model of Galí and Monacelli (2005), two general cases and one special case stand out.

The first general case is where $\sigma \eta>1$, i.e., the product of the inverse of the intertemporal substitutability in consumption of the aggregate SOE's consumption index, $\sigma>0$, and the intratemporal substitutability in consumption between domestically-produced and imported goods entering that index, $\eta>0$, is larger than unity. In this case,

$$
\omega \equiv \sigma \gamma+(1-\alpha) \underbrace{(\sigma \eta-1)}_{>1}>0
$$


so that

$$
\sigma_{\alpha} \equiv \frac{\sigma}{(1-\alpha)+\alpha \underbrace{\omega}_{>0}}>0
$$

and clearly then

$$
\kappa_{\alpha} \equiv \lambda(\underbrace{\sigma_{\alpha}}_{>0}+\varphi)>0 .
$$

The special case is where $\sigma \eta=1$, implying $\omega \equiv \sigma \gamma>0$ too and, hence, again $\sigma_{\alpha}>0$ and finally $\kappa_{\alpha}>0$. These two cases, the general and the special ones, both imply $\kappa_{\alpha}>0$. In the context of such parameter values, namely, $\sigma \eta \geq 1$ leading to $\kappa_{\alpha}>0$, therefore, the theoretically expected sign of the output gap is unambiguously positive.

However, the second general case arises where $\sigma \eta<1$. In this case,

$$
\omega \equiv \underbrace{\sigma \gamma}_{+}+\underbrace{(1-\alpha)}_{+}(\underbrace{(\sigma \eta-1)}_{-}
$$

so that if

$$
\begin{gathered}
\underbrace{\sigma \gamma}_{+}>\underbrace{(1-\alpha)}_{+} \underbrace{(1-\sigma \eta)}_{+} \\
\Leftrightarrow \frac{\gamma}{1-\alpha}+\eta>\sigma^{-1}
\end{gathered}
$$

then $\kappa_{\alpha}>0$, as before, but if the opposite is true, i.e.,

$$
\frac{\gamma}{1-\alpha}+\eta<\sigma^{-1}
$$

then $\omega<0$, so that

$$
\sigma_{\alpha} \equiv \underbrace{\frac{\overbrace{\sigma}^{+}}{(1-\alpha)}+\underbrace{\alpha \omega}_{-}}_{+}
$$

and if, further,

$$
\underbrace{\alpha-1}_{-}<\underbrace{\alpha \omega}_{-}
$$

then $\sigma_{\alpha}>0$ and so $\kappa_{\alpha}>0$, as before, but if the opposite is true, i.e.,

$$
\underbrace{\alpha-1}_{-}>\underbrace{\alpha \omega}_{-}
$$

then $\sigma_{\alpha}<0$ and

$$
\kappa_{\alpha} \equiv \underbrace{\lambda}_{+}(\underbrace{\sigma_{\alpha}}_{-}+\underbrace{\varphi}_{+})
$$


so that if $\left|\sigma_{\alpha}\right|<|\varphi|$, then $\kappa_{\alpha}>0$, as before, but if the opposite is true, i.e., $\left|\sigma_{\alpha}\right|>|\varphi|$, then $\kappa_{\alpha}<0$. The long chain of 'ifs' indicates that the case of $\kappa_{\alpha}<0$ is less probable - or may be even not plausible for appropriately chosen parameter values - than the case of $\kappa_{\alpha}>0$ in the SOE NK model of Galí and Monacelli (2005).

\section{Instrumental Variables Used in the Estimated Regressions}

In addition to the instruments below, each instrument set includes also a constant.

\section{In Table 1:}

Austria: CPI inflation lags 1 to 4, H-P filtered output gap lags 1 to 4, change in terms of trade lags 1 to 6 ;

Germany: CPI inflation lags 1 to 6 , H-P filtered output gap lags 1 to 4 , change in terms of trade lags 1 to 4 ;

Italy: CPI inflation lags 1 to 4, H-P filtered output gap lags 1 to 4, change in terms of trade lags 1 to 4 ;

France: CPI inflation lags 1 to 4, real unit labor costs lags 1 to 6 , change in terms of trade lags 1 to 4 ;

Spain: CPI inflation lags 1 to 4, H-P filtered output gap lags 1 to 6 , change in terms of trade lags 1 to 4 ;

Netherlands: CPI inflation lags 1 to 4, H-P filtered output gap lags 1 to 4 , change in terms of trade lags 1 to 6 ;

UK: CPI inflation lags 1 to 6 , H-P filtered output gap lags 1 to 6 , change in terms of trade lags 1 to 4 ;

Canada: CPI inflation lags 1 to 4, H-P filtered output gap lags 1 to 6, change in terms of trade lags 1 to 6 ;

Sweden: CPI inflation lags 1 to 6, H-P filtered output gap lags 1 to 4, change in terms of trade lags 1 to 4 ;

Switzerland: CPI inflation lags 1 to 6 , H-P filtered output gap lags 1 to 4 , change in terms of trade lags 1 to 4 .

\section{In Table 2:}


As in Table 1, except with Q-P filtered output gap instead of H-P filtered output gap.

\section{In Table 3:}

As in Table 1.

\section{In Table 4:}

As in Table 1, except with real unit labor costs instead of H-P filtered output gap.

\section{In Table 5:}

As in Table 4.

\section{In Table 6:}

As in Table 1.

\section{In Table 7:}

Austria: CPI inflation lags 1 to 6, H-P filtered output gap lags 1 to 6 , change in the bilateral USD/EUR (national currency before 1999) exchange rate lags 1 to 4;

Germany: CPI inflation lags 1 to 6, H-P filtered output gap lags 1 to 4 , change in the HWWA commodity price index lags 1 to 4 ;

Italy: CPI inflation lags 1 to 4, H-P filtered output gap lags 1 to 4, terms of trade lags 1 to 4; France: CPI inflation lags 1 to 4 , real unit labor costs lags 1 to 6 , change in terms of trade lags 1 to 4 ;

Spain: CPI inflation lags 1 to 4, real unit labor costs lags 1 to 6 , change in the HWWA commodity price index lags 1 to 4 ;

Netherlands: CPI inflation lags 1 to 6 , H-P filtered output gap lags 1 to 4 , change in the bilateral USD/EUR (national currency before 1999) exchange rate lags 1 to 4;

UK: CPI inflation lags 1 to 6 , H-P filtered output gap lags 1 to 6 , change in terms of trade lags 1 to 4 ; 
Canada: CPI inflation lags 1 to 6, H-P filtered output gap lags 1 to 6 , change in import prices lags 1 to 6 ;

Sweden: CPI inflation lags 1 to 6 , real unit labor costs lags 1 to 6 , change in the bilateral USD/SEK exchange rate lags 1 to 6 ;

Switzerland: CPI inflation lags 1 to 6 , H-P filtered output gap lags 1 to 4 , change in the bilateral USD/CHF exchange rate lags 1 to 4 .

\section{In Table 8:}

As in Table 7, except that CPI inflation starts at lag 2 instead of 1.

\section{In Table 9:}

As in Table 1.

In Table 10:

As in Table 1. 
Table 1: Estimates of the SOE NKPC

\begin{tabular}{lcccccccccc}
\hline \hline & $\beta$ & & $p$-value & $\kappa_{\alpha}$ & & $p$-value & $\alpha$ & & $p$-value & $p(J)$ \\
Austria & 0.87 & $* * *$ & 0.00 & 0.00 & & 1.00 & -0.27 & & 0.10 & 0.43 \\
Germany & 0.97 & $* * *$ & 0.00 & 0.02 & & 0.53 & 0.17 & $* * *$ & 0.00 & 0.51 \\
Italy & 1.01 & $* * *$ & 0.00 & 0.06 & & 0.26 & 0.06 & & 0.10 & 0.53 \\
France & 1.05 & $* * *$ & 0.00 & 0.19 & $* *$ & 0.02 & -0.08 & & 0.31 & 0.42 \\
Spain & 0.99 & $* * *$ & 0.00 & 0.01 & & 0.70 & -0.01 & & 0.54 & 0.77 \\
Netherlands & 0.94 & $* * *$ & 0.00 & 0.01 & & 0.79 & 0.28 & $* * *$ & 0.00 & 0.30 \\
UK & 0.87 & $* * *$ & 0.00 & 0.18 & $* *$ & 0.02 & 0.48 & $* * *$ & 0.00 & 0.46 \\
Canada & 0.99 & $* * *$ & 0.00 & 0.04 & & 0.28 & 0.14 & $*$ & 0.07 & 0.72 \\
Sweden & 0.93 & $* * *$ & 0.00 & -0.14 & $* *$ & 0.03 & 0.01 & & 0.60 & 0.54 \\
Switzerland & 0.93 & $* * *$ & 0.00 & 0.02 & & 0.67 & 0.24 & $* * *$ & 0.03 & 0.35 \\
\hline \hline
\end{tabular}

Notes: Estimated coefficients for equation (5). The estimation period is 1970:1-2007:4 (except for Austria: 1980:1-2007:4). The stars attached to the coefficient estimates show significance levels, where ${ }^{*}$ denotes significance at the $10 \%,{ }^{* *}$ at the $5 \%$ and ${ }^{* * *}$ at the $1 \%$ level. Standard errors are robust to heteroskedasticity and autocorrelation.

Table 2: Estimates of the SOE NKPC with Q-P Filtered Output Gap

\begin{tabular}{|c|c|c|c|c|c|c|c|c|c|c|}
\hline & $\overline{\bar{\beta}}$ & & $p$-value & 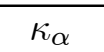 & & $\overline{p \text {-value }}$ & $\overline{\alpha \alpha}$ & & p-value & $\overline{p(\mathrm{~J})}$ \\
\hline Austria & 0.89 & $* * *$ & 0.00 & 0.02 & & 0.52 & -0.26 & & 0.12 & 0.44 \\
\hline Germany & 0.98 & $* * *$ & 0.00 & 0.00 & & 0.94 & 0.18 & $* * *$ & 0.00 & 0.54 \\
\hline Italy & 1.01 & $* * *$ & 0.00 & 0.02 & & 0.31 & 0.06 & $*$ & 0.08 & 0.60 \\
\hline France & 1.01 & $* * *$ & 0.00 & 0.12 & $*$ & 0.01 & -0.06 & & 0.40 & 0.42 \\
\hline Spain & 0.99 & $* * *$ & 0.00 & 0.00 & & 0.83 & 0.00 & & 0.70 & 0.76 \\
\hline Netherlands & 0.94 & $* * *$ & 0.00 & 0.01 & & 0.36 & 0.29 & $* * *$ & 0.00 & 0.32 \\
\hline UK & 0.86 & $* * *$ & 0.00 & 0.04 & & 0.23 & 0.47 & $* * *$ & 0.00 & 0.36 \\
\hline Canada & 0.99 & $* * *$ & 0.00 & 0.01 & & 0.44 & 0.15 & $*$ & 0.07 & 0.72 \\
\hline Sweden & 0.95 & $* * *$ & 0.00 & -0.02 & & 0.20 & 0.01 & & 0.62 & 0.52 \\
\hline Switzerland & 0.91 & $* * *$ & 0.00 & 0.01 & & 0.47 & 0.25 & $* * *$ & 0.02 & 0.36 \\
\hline
\end{tabular}

Notes: Estimated coefficients for equation (5). The estimation period is 1970:1-2007:4 (except for Austria: 1980:1-2007:4). The stars attached to the coefficient estimates show significance levels, where ${ }^{*}$ denotes significance at the $10 \%,{ }^{* *}$ at the $5 \%$ and ${ }^{* * *}$ at the $1 \%$ level. Standard errors are robust to heteroskedasticity and autocorrelation. 
Table 3: Estimates of Structural Parameters of the SOE NKPC

\begin{tabular}{lcccccccccc}
\hline \hline & $\beta$ & & $p$-value & $\theta$ & & $p$-value & $\alpha$ & & $p$-value & $p(J)$ \\
Austria & 0.87 & $* * *$ & 0.00 & 0.96 & $* * *$ & 0.00 & -0.38 & $* *$ & 0.02 & 0.43 \\
Germany & 0.97 & $* * *$ & 0.00 & 0.95 & $* * *$ & 0.00 & 0.17 & $* * *$ & 0.00 & 0.51 \\
Italy & 1.01 & $* * *$ & 0.00 & 0.88 & $* * *$ & 0.00 & 0.06 & $*$ & 0.10 & 0.53 \\
France & 1.05 & $* * *$ & 0.00 & 0.79 & $* * *$ & 0.00 & -0.08 & & 0.30 & 0.42 \\
Spain & 0.98 & $* * *$ & 0.00 & 0.94 & $* * *$ & 0.00 & -0.01 & & 0.52 & 0.77 \\
Netherlands & 0.94 & $* * *$ & 0.00 & 0.97 & $* * *$ & 0.00 & 0.28 & $* * *$ & 0.00 & 0.30 \\
UK & 0.87 & $* * *$ & 0.00 & 0.84 & $* * *$ & 0.00 & 0.48 & $* * *$ & 0.00 & 0.46 \\
Canada & 0.98 & $* * *$ & 0.00 & 0.92 & $* * *$ & 0.00 & 0.15 & $* *$ & 0.06 & 0.72 \\
Sweden & 0.97 & $* * *$ & 0.00 & 0.94 & $* * *$ & 0.00 & 0.01 & & 0.46 & 0.23 \\
Switzerland & 0.93 & $* * *$ & 0.00 & 0.95 & $* * *$ & 0.00 & 0.25 & $* *$ & 0.03 & 0.35 \\
\hline \hline
\end{tabular}

Notes: Estimated coefficients for equation (5). The estimation period is 1970:1-2007:4 (except for Austria: 1980:1-2007:4). The stars attached to the coefficient estimates show significance levels, where ${ }^{*}$ denotes significance at the $10 \%,{ }^{* *}$ at the $5 \%$ and ${ }^{* * *}$ at the $1 \%$ level. Standard errors are robust to heteroskedasticity and autocorrelation.

Table 4: Estimates of the SOE NKPC with Labor Income Share

\begin{tabular}{|c|c|c|c|c|c|c|c|c|c|c|}
\hline & $\overline{\bar{\beta}}$ & & $\overline{p \text {-value }}$ & $\bar{~} \bar{\lambda}$ & & $\overline{p \text {-value }}$ & $\alpha$ & & $p$ p-value & $\bar{~} \overline{p(J)}$ \\
\hline Austria & 0.89 & $* * *$ & 0.00 & -0.02 & & 0.72 & -0.02 & & 0.91 & 0.40 \\
\hline Germany & 0.97 & $* * *$ & 0.00 & 0.00 & & 0.91 & 0.17 & $* * *$ & 0.00 & 0.54 \\
\hline Italy & 1.02 & $* * *$ & 0.00 & 0.00 & & 0.76 & 0.23 & $* * *$ & 0.02 & 0.73 \\
\hline France & 0.98 & $* * *$ & 0.00 & 0.01 & & 0.27 & -0.04 & & 0.52 & 0.20 \\
\hline Spain & 1.00 & $* * *$ & 0.00 & 0.00 & & 0.33 & 0.01 & & 0.38 & 0.95 \\
\hline Netherlands & 0.96 & $* * *$ & 0.00 & 0.01 & & 0.54 & 0.28 & $* * *$ & 0.00 & 0.20 \\
\hline UK & 0.81 & $* * *$ & 0.00 & -0.10 & $* * *$ & 0.00 & 0.53 & $* * *$ & 0.00 & 0.27 \\
\hline Canada & 0.99 & $* * *$ & 0.00 & 0.00 & & 0.81 & 0.00 & & 0.98 & 0.72 \\
\hline Sweden & 0.93 & $* * *$ & 0.00 & -0.02 & & 0.24 & 0.01 & & 0.61 & 0.46 \\
\hline
\end{tabular}

Notes: Estimated coefficients for equation (4). The estimation period is 1970:1-2007:4 (except for Austria: 1980:1-2007:4; Italy: 1975:1-2007:4; Spain: 1980:1-2007:4). The stars attached to the coefficient estimates show significance levels, where ${ }^{*}$ denotes significance at the $10 \%,{ }^{* *}$ at the $5 \%$ and ${ }^{* * *}$ at the $1 \%$ level. Standard errors are robust to heteroskedasticity and autocorrelation. 
Table 5: Estimates of Structural Parameters of the SOE NKPC with the Labor Income Share

\begin{tabular}{lcccccccccc}
\hline \hline & $\beta$ & & $p$-value & $\theta$ & & $p$-value & $\alpha$ & & $p$-value & $p(J)$ \\
Austria & 0.90 & $* * *$ & 0.00 & 0.84 & $* * *$ & 0.00 & 0.06 & & 0.69 & 0.29 \\
Germany & 0.97 & $* * *$ & 0.00 & 0.97 & $* * *$ & 0.00 & 0.17 & $* * *$ & 0.00 & 0.37 \\
Italy & 1.03 & $* * *$ & 0.00 & 1.01 & $* * *$ & 0.00 & 0.27 & $* * *$ & 0.00 & 0.76 \\
France & 0.97 & $* * *$ & 0.00 & 0.80 & & 0.23 & 0.63 & $* * *$ & 0.00 & 0.24 \\
Spain & 1.00 & $* * *$ & 0.00 & 0.95 & $* * *$ & 0.00 & 0.01 & & 0.33 & 0.90 \\
Netherlands & 0.96 & $* * *$ & 0.00 & 0.92 & $* * *$ & 0.00 & 0.28 & $* * *$ & 0.00 & 0.20 \\
UK & 0.97 & $* * *$ & 0.00 & 0.80 & & 0.23 & 0.63 & $* * *$ & 0.00 & 0.24 \\
Canada & 1.01 & $* * *$ & 0.00 & 0.91 & $* * *$ & 0.00 & 0.15 & $* *$ & 0.03 & 0.91 \\
Sweden & 0.95 & $* * *$ & 0.00 & 0.82 & $* *$ & 0.04 & 0.01 & & 0.60 & 0.42 \\
\hline \hline
\end{tabular}

Notes: Estimated coefficients for equation (4). The estimation period is 1970:1-2007:4 (except for Austria: 1980:1-2007:4). The stars attached to the coefficient estimates show significance levels, where ${ }^{*}$ denotes significance at the $10 \%,{ }^{* *}$ at the $5 \%$ and ${ }^{* * *}$ at the $1 \%$ level. Standard errors are robust to heteroskedasticity and autocorrelation.

Table 6: Estimates of the SOE NKPC with the First Difference of the Terms of Trade

\begin{tabular}{lcccccccccc}
\hline \hline & $\beta_{\Delta}$ & & $p$-value & $\kappa_{\alpha \Delta}$ & & $p$-value & $\alpha_{\Delta}$ & & $p$-value & $p(J)$ \\
Austria & 0.89 & $* * *$ & 0.00 & 0.02 & & 0.65 & 0.35 & $* *$ & 0.02 & 0.45 \\
Germany & 0.95 & $* * *$ & 0.00 & 0.03 & & 0.29 & 0.18 & $* * *$ & 0.00 & 0.33 \\
Italy & 1.01 & $* * *$ & 0.00 & 0.08 & & 0.10 & 0.05 & & 0.29 & 0.41 \\
France & 1.06 & $* * *$ & 0.00 & 0.15 & $* *$ & 0.02 & 0.09 & $* *$ & 0.02 & 0.67 \\
Spain & 0.99 & $* * *$ & 0.00 & 0.01 & & 0.60 & 0.01 & & 0.54 & 0.76 \\
Netherlands & 0.96 & $* * *$ & 0.00 & -0.01 & & 0.84 & 0.31 & $* * *$ & 0.00 & 0.19 \\
UK & 0.83 & $* * *$ & 0.00 & 0.30 & $* * *$ & 0.00 & 0.55 & $* * *$ & 0.00 & 0.32 \\
Canada & 1.00 & $* * *$ & 0.00 & 0.03 & & 0.34 & 0.04 & & 0.42 & 0.64 \\
Sweden & 0.92 & $* * *$ & 0.00 & -0.14 & $* *$ & 0.03 & 0.02 & & 0.61 & 0.55 \\
Switzerland & 0.81 & $* * *$ & 0.00 & -0.04 & & 0.43 & 0.16 & $* *$ & 0.03 & 0.25 \\
\hline \hline
\end{tabular}

Notes: Estimated coefficients for $\pi_{t}=\beta_{\Delta} E_{t} \pi_{t+1}+\kappa_{\alpha \Delta} x_{t}+\alpha_{\Delta} \Delta s_{t}$. The estimation period is 1970:12007:4 (except for Austria: 1980:1-2007:4). The stars attached to the coefficient estimates show significance levels, where ${ }^{*}$ denotes significance at the $10 \%,{ }^{* *}$ at the $5 \%$ and ${ }^{* * *}$ at the $1 \%$ level. Standard errors are robust to heteroskedasticity and autocorrelation. 
Table 7: Closed Economy NKPC

\begin{tabular}{lccccccc}
\hline \hline & $\beta$ & & $p$-value & $\kappa$ & & $p$-value & $p(J)$ \\
Austria & 0.91 & $* * *$ & 0.00 & 0.04 & & 0.28 & 0.53 \\
Germany & 0.99 & $* * *$ & 0.00 & 0.05 & $*$ & 0.08 & 0.47 \\
Italy & 1.00 & $* * *$ & 0.00 & 0.12 & $* *$ & 0.02 & 0.42 \\
France & 1.03 & $* * *$ & 0.00 & 0.13 & $* *$ & 0.02 & 0.30 \\
Spain & 1.02 & $* * *$ & 0.00 & 0.05 & & 0.22 & 0.84 \\
Netherlands & 0.97 & $* * *$ & 0.00 & 0.01 & & 0.66 & 0.26 \\
UK & 0.81 & $* * *$ & 0.00 & 0.48 & $* * *$ & 0.00 & 0.21 \\
Canada & 1.00 & $* * *$ & 0.00 & 0.05 & & 0.10 & 0.80 \\
Sweden & 1.00 & $* * *$ & 0.00 & 0.11 & & 0.42 & 0.51 \\
Switzerland & 0.95 & $* * *$ & 0.00 & -0.01 & & 0.74 & 0.23 \\
\hline \hline
\end{tabular}

Notes: Estimated coefficients for $\pi_{t}=\beta E_{t} \pi_{t+1}+\kappa x_{t}$. The estimation period is 1970:1-2007:4 (except for Austria: 1980:1-2007:4). The stars attached to the coefficient estimates show significance levels, where ${ }^{*}$ denotes significance at the $10 \%,{ }^{* *}$ at the $5 \%$ and ${ }^{* * *}$ at the $1 \%$ level. Standard errors are robust to heteroskedasticity and autocorrelation.

Table 8: Hybrid Closed Economy NKPC

\begin{tabular}{lcccccccccc}
\hline \hline & $\gamma_{f}$ & & $p$-value & $\gamma_{b}$ & & $p$-value & $\kappa$ & & $p$-value & $p(J)$ \\
Austria & 0.71 & $* * *$ & 0.00 & 0.29 & $* * *$ & 0.00 & 0.01 & & 0.66 & 0.47 \\
Germany & 0.55 & $* * *$ & 0.00 & 0.44 & $* * *$ & 0.00 & 0.02 & & 0.19 & 0.25 \\
Italy & 0.62 & $* * *$ & 0.00 & 0.38 & $* * *$ & 0.00 & 0.07 & $* *$ & 0.04 & 0.29 \\
France & 0.40 & $* * *$ & 0.00 & 0.60 & $* * *$ & 0.00 & -0.01 & & 0.75 & 0.24 \\
Spain & 0.79 & $* * *$ & 0.00 & 0.23 & & 0.32 & 0.06 & & 0.10 & 0.74 \\
Netherlands & 0.54 & $* * *$ & 0.00 & 0.46 & $* * *$ & 0.00 & 0.01 & & 0.75 & 0.19 \\
UK & 0.58 & $* * *$ & 0.00 & 0.23 & $* * *$ & 0.01 & 0.32 & $* * *$ & 0.00 & 0.13 \\
Canada & 0.67 & $* * *$ & 0.00 & 0.33 & $* * *$ & 0.00 & 0.04 & $*$ & 0.07 & 0.66 \\
Sweden & 0.69 & $* * *$ & 0.00 & 0.33 & $* * *$ & 0.00 & 0.14 & & 0.32 & 0.40 \\
Switzerland & 0.34 & $* * *$ & 0.00 & 0.62 & $* * *$ & 0.00 & 0.00 & & 0.92 & 0.14 \\
\hline \hline
\end{tabular}

Notes: Estimated coefficients for $\pi_{t}=\gamma_{f} E_{t} \pi_{t+1}+\gamma_{b} \pi_{t-1}+\kappa x_{t}$. The estimation period is 1970:1-2007:4 (except for Austria: 1980:1-2007:4). The stars attached to the coefficient estimates show significance levels, where ${ }^{*}$ denotes significance at the $10 \%,{ }^{* *}$ at the $5 \%$ and ${ }^{* * *}$ at the $1 \%$ level. Standard errors are robust to heteroskedasticity and autocorrelation. 
Table 9: SOE NKPC: 1970:1-1986:4

\begin{tabular}{lcccccccccc}
\hline \hline & $\beta$ & & $p$-value & $\kappa_{\alpha}$ & & $p$-value & $\alpha$ & & $p$-value & $p(J)$ \\
Austria & 0.30 & $* * *$ & 0.00 & -0.56 & $* * *$ & 0.00 & 0.33 & $*$ & 0.09 & 0.71 \\
Germany & 0.99 & $* * *$ & 0.00 & 0.07 & $* *$ & 0.03 & 0.07 & $* *$ & 0.04 & 0.77 \\
Italy & 1.00 & $* * *$ & 0.00 & 0.08 & & 0.38 & 0.04 & & 0.23 & 0.78 \\
France & 1.03 & $* * *$ & 0.00 & 0.10 & $* *$ & 0.03 & -0.04 & & 0.37 & 0.72 \\
Spain & 0.98 & $* * *$ & 0.00 & 0.08 & & 0.47 & 0.00 & & 0.79 & 0.63 \\
Netherlands & 0.97 & $* * *$ & 0.00 & 0.20 & & 0.11 & 0.21 & $* *$ & 0.01 & 0.58 \\
UK & 0.90 & $* * *$ & 0.00 & 0.24 & & 0.03 & 0.47 & $* * *$ & 0.00 & 0.80 \\
Canada & 0.98 & $* * *$ & 0.00 & 0.09 & & 0.18 & 0.08 & & 0.10 & 0.90 \\
Sweden & 0.91 & $* * *$ & 0.00 & -0.44 & $* * *$ & 0.00 & 0.04 & $* *$ & 0.06 & 0.63 \\
Switzerland & 0.86 & $* * *$ & 0.00 & -0.14 & $* *$ & 0.01 & 0.10 & & 0.41 & 0.69 \\
\hline \hline
\end{tabular}

Notes: Estimated coefficients for equation (5). The estimation period is 1970:1-1986:4 (except for Austria: 1980:1-1990:4; Germany: 1970:1-1990:4). The stars attached to the coefficient estimates show significance levels, where ${ }^{*}$ denotes significance at the $10 \%,{ }^{* *}$ at the $5 \%$ and ${ }^{* * *}$ at the $1 \%$ level. Standard errors are robust to heteroskedasticity and autocorrelation.

Table 10: SOE NKPC: 1987:1-2007:4

\begin{tabular}{|c|c|c|c|c|c|c|c|c|c|c|}
\hline & $\beta$ & & $p$-value & $\kappa_{\alpha}$ & & $p$-value & $\alpha$ & & $p$-value & $p(J)$ \\
\hline Austria & 0.96 & $* * *$ & 0.00 & 0.00 & & 0.99 & 0.12 & & 0.58 & 0.77 \\
\hline Germany & 0.83 & $* * *$ & 0.00 & -0.03 & & 0.44 & 0.06 & & 0.25 & 0.46 \\
\hline Italy & 1.04 & $* * *$ & 0.00 & 0.01 & & 0.80 & 0.14 & $* *$ & 0.05 & 0.35 \\
\hline France & 0.96 & $* * *$ & 0.00 & 0.01 & & 0.71 & 0.01 & & 0.91 & 0.25 \\
\hline Spain & 0.99 & $* * *$ & 0.00 & -0.05 & $* *$ & 0.02 & 0.01 & & 0.65 & 0.90 \\
\hline Netherlands & 0.86 & $* * *$ & 0.00 & -0.07 & $* *$ & 0.03 & 0.27 & $* * *$ & 0.00 & 0.25 \\
\hline UK & 0.72 & $* * *$ & 0.00 & 0.24 & $* *$ & 0.03 & 0.84 & $* * *$ & 0.00 & 0.68 \\
\hline Canada & 0.97 & $* * *$ & 0.00 & 0.02 & & 0.65 & 0.05 & & 0.40 & 0.91 \\
\hline Sweden & 0.95 & $* * *$ & 0.00 & 0.01 & & 0.89 & 0.05 & & 0.48 & 0.55 \\
\hline Switzerland & 1.03 & $* * *$ & 0.00 & 0.10 & $*$ & 0.07 & 0.12 & & 0.13 & 0.26 \\
\hline
\end{tabular}

Notes: Estimated coefficients for equation (5). The estimation period is 1987:1-2007:4 (except for Austria and Germany: 1991:1-2007:4). The stars attached to the coefficient estimates show significance levels, where ${ }^{*}$ denotes significance at the $10 \%,{ }^{* *}$ at the $5 \%$ and ${ }^{* * *}$ at the $1 \%$ level. Standard errors are robust to heteroskedasticity and autocorrelation. 